http://jmscr.igmpublication.org/home/ ISSN (e)-2347-176x ISSN (p) 2455-0450

crossref DOI: https://dx.doi.org/10.18535/jmscr/v8i11.05

\title{
Clinical Presentation, Scoring and Lower Gastrointestinal Endoscopic Findings of Haemorrhoids
}

Authors

\section{Dr Mary Prescilla V.B ${ }^{1^{*}}$, Dr.Kabalimurthy $\mathbf{J}^{2}$, Dr Sundar Prakash $\mathbf{S}^{3}$, Dr Kamal Kumar $\mathbf{K}^{\mathbf{1}}$, Dr Jospin Amala $\mathbf{A}^{\mathbf{1}}$, Dr Aravindhan $\mathbf{M}^{\mathbf{1}}$}

${ }^{1}$ Post Graduate, Department of General Surgery, Rajah Muthiah Medical College and Hospital, Chidambaram

${ }^{2}$ Professor, Department of General Surgery, Rajah Muthiah Medical College and Hospital, Chidambaram

${ }^{3}$ Assosciate professor, Department of General Surgery, Rajah Muthiah Medical College and Hospital,

Chidambaram

*Corresponding Author

Dr Mary Prescilla V.B.

\begin{abstract}
The study was conducted to analyse the clinical presentation of haemorrhoids, its association to diet and type of toilet and its clinical evaluation by Digital Per Rectal Examination, Proctosopy, Lower Gastrointestinal Endoscopy- Sigmiodoscopy/ Colonoscopy in finding the grades, classification, associated findings and its treatment.

Methods: We conducted this study in the department of General Surgery, Rajah Muthiah Medical College from October 2018 to September 2020. 100 patients diagnosed with haemorrhoids were studied in terms of clinical presentation and evaluation with various other studies, the results obtained were correlated.

Results: 75 patients presented with Bleeding per rectum which is the most common presentation followed by prolapse in 65 patients. Pain during defecation was present in 51 patients and pruritus 2 patients. Patients Commonly presented with Grade 2 haemorrhoids 53\%. Secondary haemorrhoids was seen in 7 patients.18 patients had associated fissure and 4 patients with polyp. 93 patients underwent Haemorrhoidectomy.

7 patients were given Injection sclerotherapy. Among them, both Haemorrhoidectomy and injection sclerotherapy was given to 15 patients.

Conclusion: Haemorrhoids is a benign disease of all ages and sexes. It is diagnosed mainly by clinical examination. It should be evaluated and based on the severity, grading, relation to dentate line the mode of treatment is chosen. Even after treatment, recurrence are common. Patients usually will consult during acute phase especially for pain. Decision making and certain actions are are very important in understanding and then to treat it.

Keywords: Haemorrhoids, (Digital) Per Rectal Examination, Proctoscopy, Sclerotherapy.
\end{abstract}

\section{Introduction}

One of the most common anorectal disease is Haemorrhoids, which troubles people since early times. Though it is not fatal, it causes physical and pschological problem which is siginificant that affect the Quality of Life. Haemorrhoids 
formation is to be prevented by means of avoiding and eliminating the risk factors and life style modifications.

\section{Methods}

The present study was conducted in the department of General Surgery, Rajah Muthiah Medical College from October 2018 to September 2020. 100 Patients diagnosed and admitted with haemorrhoids of both the gender with any grade of haemorrhoids are included and were studied. Pregnant lady, patients with portal hypertension, gastrointestinal carcinoma were excluded. After thorough history taking as per proforma, physical examination and local examination of anus and rectum, proctoscopic examination, sigmoidoscopy/ colonoscopy was done. Took Routine blood investigations and Patients were a posted for surgery after getting assessment and followed up the patient.

\section{Results}

Figure 1: Clinical Presentation of Haemorrhoids

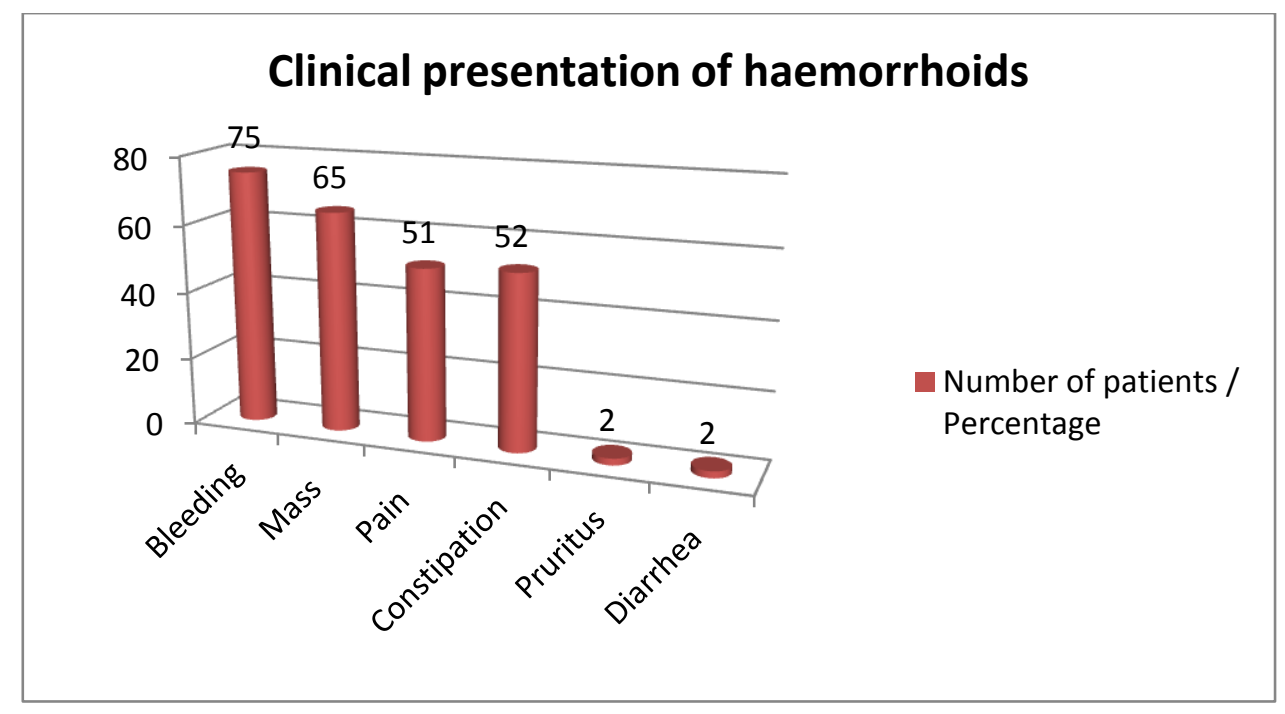

Among 100 patients, most of the patients presented with bleeding per rectum as the main symptom accounting to $75 \%$. 65 patients presented with mass descending during defecation. 51 patients came with history of pain.
Constipation was present in 52 patients and 2 patients presented with pruritus. 2 patients had diarrhea history. Altered bowel habits contribute to haemorrhoids while constipation predominates

Figure 2: Comparison of Diet and Clinical Presentation

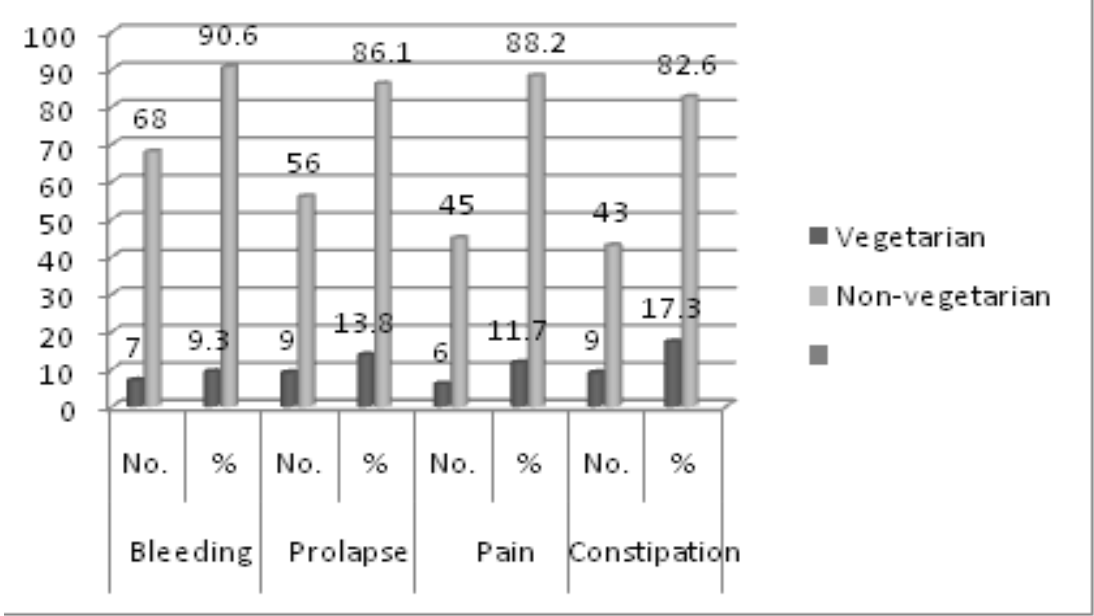


From this study, the clinical presentation like bleeding $(90.6 \%)$, prolapsed $(86.1 \%)$, pain $(88.2 \%)$ and constipation $(82.6 \%)$ are common among non vegetarian than vegetarian. Prolapse / mass per anum (56\%) is the most common presentation among vegetarian rather than bleeding during defecation. $\mathrm{P}$ value is less than 0.05 and it is significant.

Figure 3: Comparison of Type of Toilet and Clinical Presentation

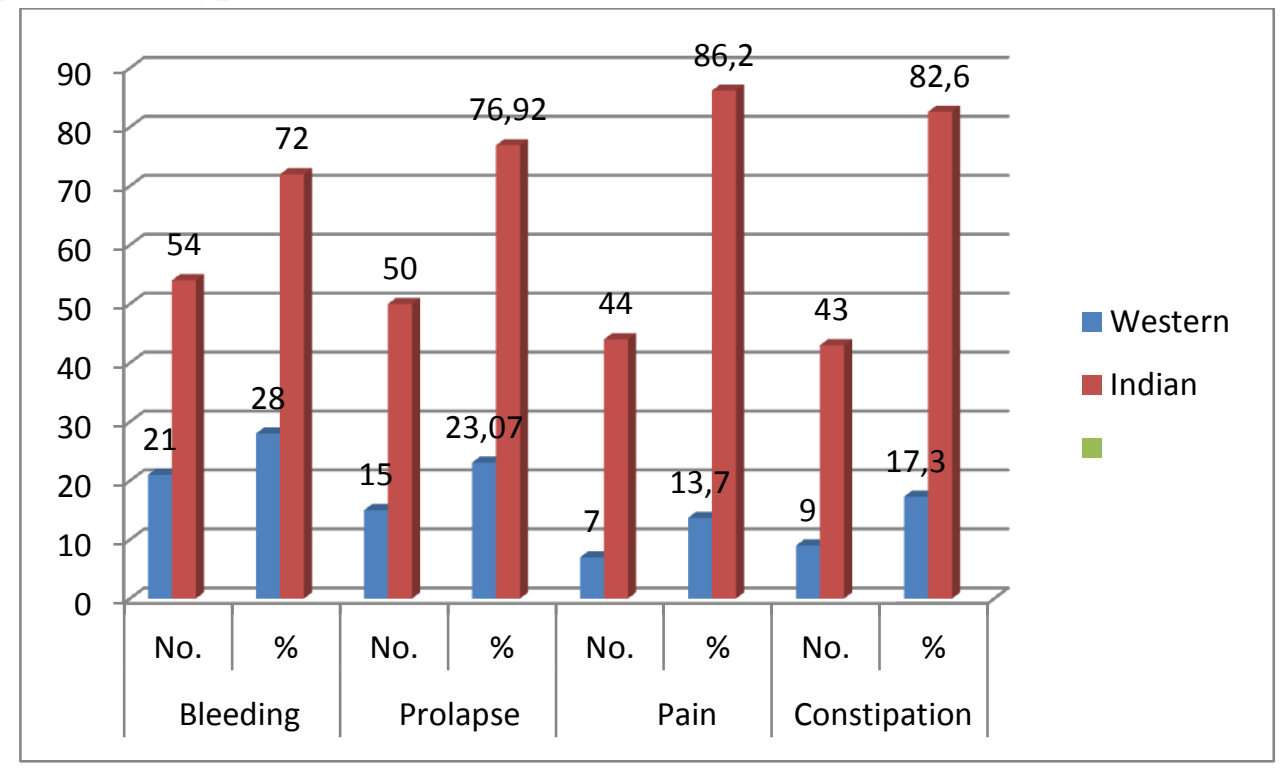

In this study, the clinical presentations are common in people using Indian toilet. Bleeding is the most common presentation in both the groups with $28 \%$ in western toilet users and $72 \%$ in Indian toilet users. The $\mathrm{P}$ value is 0.002 which is less than 0.05 and it is significant.

Figure 4: Grades of Haemorrhoids

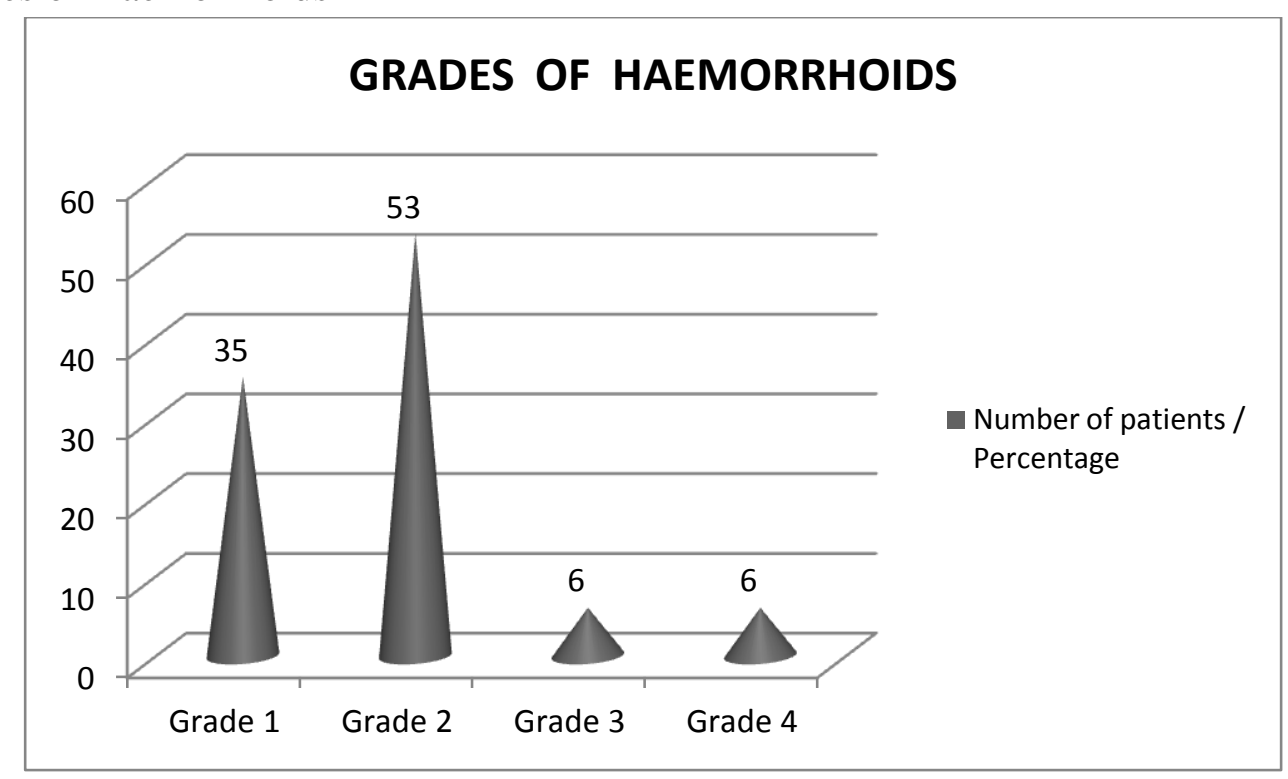

Among 100 patients, 35 patients did not have any mass descending during defecation. 53 patients had pile mass descending per anus while defecation ,but reduces on its own. 6 patients had mass descending during defecation but reduced manually. 6 patients had irreducible prolapsed mass. Among them 2 patients had Thrombosed haemorrhoids. Secondary haemorrhoids (based on its position) were present in 7 patients. 
Figure 5: Lower Gastrointestinal Endoscopy Findings

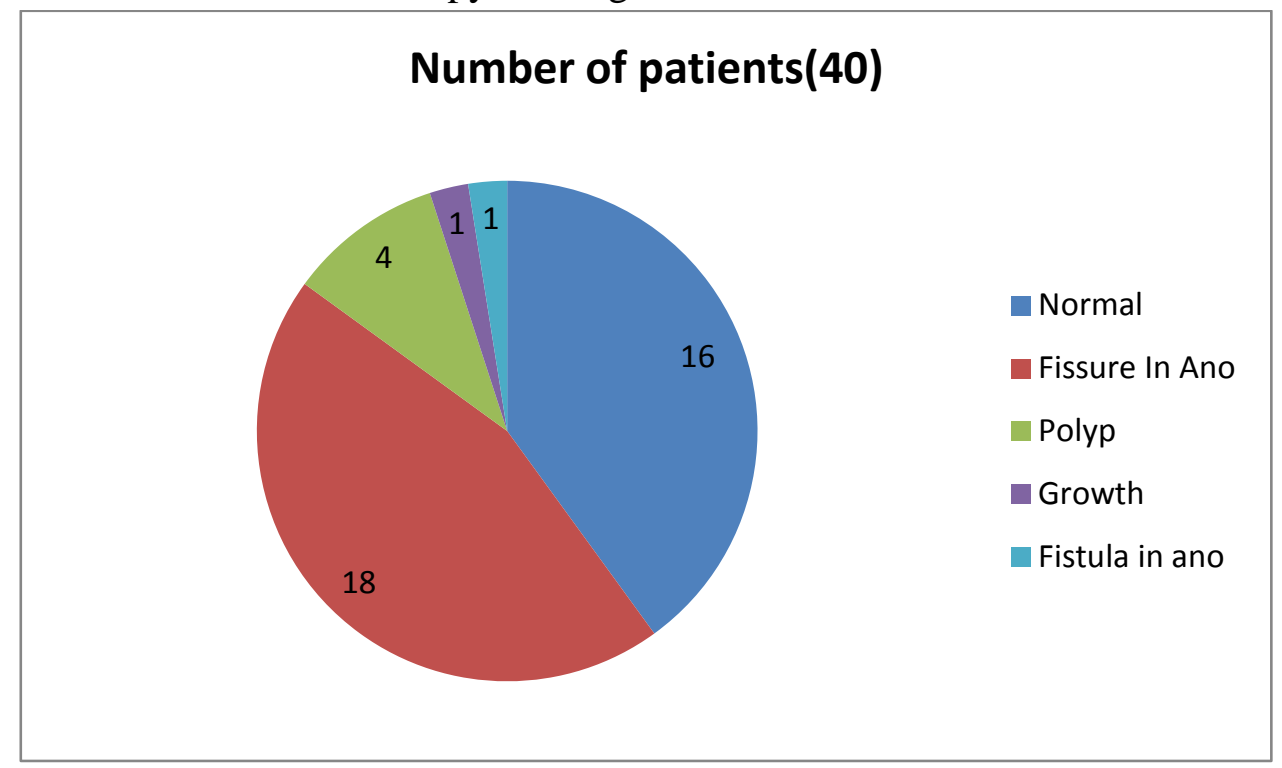

Among these patients Lower GastroIntestinal Endoscopy was done in 40 patients. Normal endoscopic finding was seen in 16 patients (40\%). Fissure in ano was observed in 18 patients (45\%), polyp (10\%) was seen in 4 patients, Fistula in ano in 1 patient $(2.5 \%)$ and rectal growth in 1 patient $(2.5 \%)$.

Figure 6: Haemorrhoid Severity Score

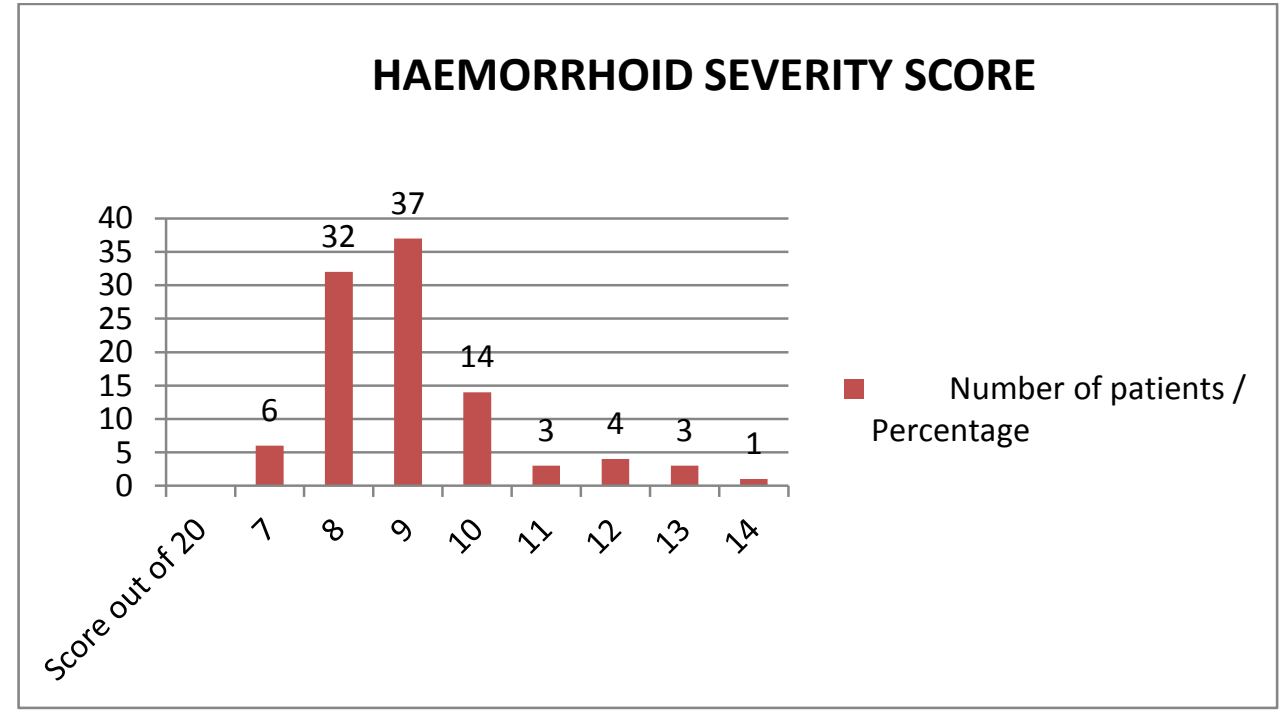

Haemorrhoid Severity Score based on PNR-Bleed classification $^{17}$ is calculated in which, maximum number of patients had a score of 9 and it is seen in 37 patients. Secondly, score of eight is present in 32 patients. A single patient has a high score of 14. Low score of 7 is in seen 6 patients. A score of 12 in 4 patients and

A score of 11 is accounted in 3 patients. 3 patients had haemorrhoid severity score of 13 .

7 patients were given injection sclerotherapy for grade 1 / grade 2 haemorrhoids. Haemorrhoidectomy was done in 93 patients. Among the patients who underwent haemorrhoidectomy, Injection sclerotherapy was also given in 8 patients who had different grades of haemorrhoids in other positions. Partial lateral internal sphincterotomy was also done in patients who had associated fissure and increased sphincter tone. 


\section{Discussion}

Haemorrhoids is common among middle aged males. There are various risk factors contributing to haemorrhoids. Patients may present in different presentations. In our study $75 \%$ had bleeding during defecation, $65 \%$ had mass per anum. Pain was present in 51 patients. Constipation was predominant in $52 \%$ while $2 \%$ had pruritus. In Ali $\mathrm{S} A$ et al, bleeding per rectum and mass per rectum was $85 \%$, pain was $77.5 \%$, pruritus and diarrhea was $12.5 \%$. In Johannsson et al, $44 \%$ had bleeding, $24 \%$ prolapse, pain in $12 \%$ and pruritus in $5 \%$. This is in accordance With other studies. In Leicester et al, bleeding was observed in $35 \%$, prolapse in $21 \%$, pain in $19 \%$, pruritus in $6 \%$. Altered bowel habits was present in 53\%. Among them $51 \%$ had constipation and $2 \%$ had loose stools. In Ali S A et al, 60\% had constipation which is similar to this study.

Table 1: Comparison Study on Modes of Presentation

\begin{tabular}{|c|c|c|c|c|c|}
\hline & $\begin{array}{c}\text { Johannsson et } \\
\text { al }^{6}(140)\end{array}$ & $\begin{array}{c}\text { Ravindranath } G \\
\text { G et } \mathrm{al}^{3}(40)\end{array}$ & $\begin{array}{c}\text { Ali } S \text { A et al } \\
(40)\end{array}$ & $\begin{array}{c}\text { Coulibaly et al } \\
(140)\end{array}$ & $\begin{array}{l}\text { This study } \\
\text { (100) }\end{array}$ \\
\hline Bleeding & $44 \%$ & $96.8 \%$ & $85 \%$ & $52.14 \%$ & $75 \%$ \\
\hline Mass & $24 \%$ & $93.7 \%$ & $85 \%$ & $17.86 \%$ & $65 \%$ \\
\hline Constipation & - & $55 \%$ & $42.5 \%$ & $46.43 \%$ & $52 \%$ \\
\hline Pain & $12 \%$ & $76.2 \%$ & $77.5 \%$ & $20.71 \%$ & $51 \%$ \\
\hline Pruritus & $5 \%$ & - & $12.5 \%$ & $9 \%$ & $2 \%$ \\
\hline Diarrhea & - & - & - & - & $2 \%$ \\
\hline
\end{tabular}

Half of the patients $53 \%$ had grade 2 haemorrhoids.35\% did not have any mass descending during defecation. $53 \%$ had pile mass descending per anus while defecation, but reduces on its own. $6 \%$ had mass descending during defecation but reduced manually. $6 \%$ had irreducible prolapsed mass. Among them $2 \%$ had Thrombosed haemorrhoids.

Secondary haemorrhoids (based on its position) were present in $7 \%$. Mudassir Ahmad Khan et al ${ }^{7}$ formulated PNR-Bleed classification and arrived at Haemorrhoid Severity Score.

Fissure in ano was associated in 18 patients along with haemorrhoids. Among them 16 consumes non vegetarian $(88.8 \%)$.

Colonoscopy/ Sigmoidoscopy findings were observed in 24 patients. The findings observed during the procedure are fissure in ano in 18 patients, polyp in 4 patients and growth in 1 patient. 16 patients had normal findings.

Among 100 patients, 15 patients were given injection sclerotherapy for grade $1 /$ grade 2 haemorrhoids. Haemorrhoidectomy was done in 93 patients. Among the patients who underwent haemorrhoidectomy, Injection sclerotherapy was given in 8 patients who had grade 1 or 2 in addition. Partial lateral internal sphincterotomy was also done in patients who had associated fissure and increased sphincter tone. ${ }^{8,10}$ Haemorrhoidectomy ${ }^{5}$ and injection sclerotherapy were given as treatment. ${ }^{9}$ No patients came with recurrence.

\section{Conclusion}

Incidence is more in Non vegetarian people.

Indian toilet are being commonly used.

Bleeding per rectum is the most common presentation among the patients.

Prolapse is the most common presentation among vegetarian rather than bleeding during defecation.

Grade 2 Haemorrhoids being the most common type.

Fissure in ano was commonly encountered along with haemorrhoids. ${ }^{8}$

Haemorrhoids being a distressing problem, it should be evaluated and based on the severity, grading, relation to dentate line the mode of treatment is chosen. Even after treatment, recurrence are common unless the precipitating or risk factor is eliminated. Modifiable or preventable factors are to be aimed at. Patients usually will consult during acute phase especially 
for pain. Decision making and certain actions are are very important in understanding and then to treat it.

Funding: No funding sources

Conflict of interest: None declared.

\section{References}

1. Asif Ali S A, Mohammad Fazelul Rahman Shoeb - Study of risk factors and clinical features of hemorrhoids International Surgery Journal 2017 Jun;4(6):1936-1939 .

2. Rizwan Mansoor Khan, Malik Itrat, A.H. Ansari, M. Zulkifle, Ehtisham- A study on assosciated risk factors of haemorrhoidsJournal of biological and scientific opinion vol 3(1) 2015.

3. Ravindranath G G, Rahul B G- Prevalence and risk factors of haemorrhoids in a semiurban centre. Int . Surg J.2018 ; 5:2- 496499.

4. Coulibaly A, Kafando R, Somada K S et al - The Haemorrhoids 'Pathology: Epidemiological, Diagnostic, Therapeutic And Evolutionary Aspects - Open journal of gastroenterology,2016,6,343-352.

5. Indru $\mathrm{T}$ Khubchandani- operative haemorrhoidectomy surg.cli of North America dec 88-68.

6. Johanson J.F. and Sonnenberg, A. The prevalence of haemorrhoids an constipation. An epidemiological study. Gastroenterology , 98, 380-386.

7. Mudassir Ahmad Khan, Nisar A. Chowdri, Fazal Q.Parry, Rauf AW, Asif Mehraj, Arshad Baba, Mushtaq Laway- "PNRBleed" classification and Hemorrhoid Severity Score - a novel attempt at classifying the hemorrhoids- Journal Of Colpoproctology 2020 - 428.
8. Arabi Y Alexander - Williams J Keighley MRB. Anal pressures in hemorrhoids and anal fissure .American Journal of surgery 1977;134:608- 610.

9. Anderson H.G(1909) the Injection treatment of hemorrhoids practitioners 113,399.

10. Shafik A. A new concept of the anatomy of the anal sphincter mechanism and the physiology of defecation. The external anal sphincter : a triple loop system. Invest URO.19755:12:412-9. 